\title{
El comercio electrónico en tiempos de COVID-19, en el entorno de los negocios de la región 6.
}

\author{
Consequences on employment due to the impact of COVID-19, in the \\ business environment of Region 6.
}

Edison Becerra Molina. ${ }^{1}$, Yolanda Jaramillo Calle. ${ }^{2}, \&$ María Eliza Flores. ${ }^{3}$

\begin{abstract}
DOI: https://doi.org/10.33262/cienciadigital.v5i4.1872

Introduction. Electronic commerce has been a very important business model within the COVID-19 pandemic. In our region, this model has not yet been fully established because the customer still mistrusts it. Target. Analyze the effects that eCommerce is causing due to the impact of the pandemic on MSMEs in the region 6. Methodology. The research design started from the positivist research paradigm, non-experimental and transectional field design with documentary support, descriptive research level, the population was 77,289 and the sample 471, the questionnaire instrument was used, it was validated by trial of experts with experience in the employment area and methodology, rating validity, clarity, coherence, and relevance. Results. Among the most frequently required results through electronic commerce in the presence of the coronavirus, were food $30.13 \%$, supermarkets $26.10 \%$, pharmacies $19.39 \%$, sports sector $8.64 \%$, which includes equipment such as electronic treadmills, bicycles , clothing, shoes, among others; others $7.87 \%$, which includes audiovisual content, tablets, computers, cell phones, and other articles; and minor tools, laundry $4.41 \%$ and liquor stores $3.45 \%$, in short, the clearest

\footnotetext{
1 Universidad Católica de Cuenca, Carrera de Contabilidad y Auditoría, provincia,Azuay, código, jbecerram@ucacue.edu.ec, Orcid.Org ID: 0000-0002-6397-9493

${ }_{2}$ Universidad Católica de Cuenca, Carrera de Contabilidad y auditoría, provincia Azuay, código, cjaramillo@ ucacue.edu.ec, Orcid.Org ID: 0000-0003-4639-0318

3 Universidad Católica de Cuenca, Carrera de Contabilidad y auditoría, provincia Azuay, código, mefloresf@ucacue.edu.ec Orcid.Org ID: 0000-0002-7348-4523
} 
change is that more people have made the decision to opt for online purchases to avoid going out and exposing themselves. Conclution. The effects of a globalized world, where the digital age is everything today, give way to new consumption patterns and strengthening the value chain of online sales, are just some of the balances that the coronavirus has thrown that, although it has affected health and multiple economic activities, it is also stimulating creativity and the development of business solutions that will contribute to the growth of electronic commerce in the short term that business generates.

Keywords: COVID-19, Economy, MSMEs, Unemployment, Labor restrictions, Regulatory incentives.

\section{Resumen}

Introducción. El comercio electrónico ha sido un modelo de negocio de mucha importancia dentro de la pandemia del COVID-19. En nuestra región este modelo aún no se ha asentado del todo debido a que el cliente aún desconfía. Objetivo. Analizar los efectos que está provocando el eCommerce debido al impacto de la pandemia en las Mipymes de la región 6. Metodología. El diseño de la investigación partió del paradigma de investigación positivista, diseño de campo no experimental y transeccional con apoyo documental, nivel de investigación descriptiva, la población fue 77.289 y la muestra 471, se utilizó el instrumento del cuestionario, el mismo fue validado mediante juicio de expertos con experiencia en el área empleo y metodología, calificando validez, claridad, coherencia, y relevancia. Resultados. Entre los resultados con mayor frecuencia requeridos mediante comercio electrónico ante la presencia del coronavirus, fueron alimentos $30,13 \%$, supermercados $26,10 \%$, farmacias $19,39 \%$, sector deportivo $8,64 \%$, que incluye equipos como caminadoras electrónicas, bicicletas, indumentaria, zapatos, entre otros; otros el 7,87\%, que incluye contenido audiovisuales, tablets, computadoras, celulares, y demás artículos; y herramientas menores, lavandería $4,41 \%$ y licoreras $3,45 \%$, en definitiva el cambio más claro es que más personas han tomado la decisión de optar por las compras online para evitar salir a la calle y exponerse. Conclusión. Los efectos de un mundo globalizado, en donde la era digital lo es todo hoy en día, dan salida a nuevas pautas de consumo y fortalecimiento de la cadena de valor de las ventas en línea, son solo algunos de los saldos que ha arrojado el coronavirus que, si bien ha afectado la salud y múltiples actividades económicas, también está estimulando la creatividad y el desarrollo de soluciones de negocios que contribuirán al crecimiento del comercio electrónico a corto plazo que generan los negocios.

Palabras claves: COVID-19, Comercio electrónico, internet, economía, innovación.

\section{Introducción}

La pandemia del COVID-19, ha dado lugar a nuevas pautas de consumo y al afianzamiento de la cadena de valor de las ventas en línea, esto implica una teoría 
empresarial que sirve para estimar el valor de los productos o servicios disponibles para la venta, que produce una empresa, habitualmente, compuesta por eslabones, en materia de compras, almacén, diseño, producción, ventas, inversiones, entre otros. La pandemia si bien ha afectado la salud y variadas actividades económicas de los sectores productivos empresariales, también está estimulando la creatividad y el desarrollo de soluciones de negocios que contribuirán al crecimiento del comercio electrónico a corto plazo y mediano plazo.

El virus ha hecho que la rutina diaria de las personas y negocios cambien hacia una jornada de estricta seguridad, distanciamiento y cuidado. Esta nueva normalidad hizo que la socialización entre la gente sea al mínimo posible, a fin de reducir la propagación del virus. Así mismo, muchas Mipymes tuvieron que cerrar sus actividades debido al poco flujo de clientes y usuarios y a los bajos ingresos por falta de ventas, que se estaban percibiendo. Por otra parte, algunas empresas modificaron sus modelos de negocios, con el objetivo de continuar brindando sus productos y/o servicios. Allí que una buena parte de negocios al ver que no podían cubrir la demanda de forma presencial optaron por trabajar de forma online, usando principalmente las redes sociales como Facebook, Instagram y, WhatsApp, y sitios web. Pero esta forma de vender y comprar productos y/o servicios no es de ahora, el comercio online o también conocido como e-commerce, es una alternativa que, con la ayuda de los avances tecnológicos, ha venido a simplificar los procesos de compra-venta, teniendo aprobación y aceptación entre los consumidores y las empresas a nivel local y regional.

En tal sentido, en el caso de nuestro país el Ecuador, y concretamente la región 6 del austro, el modelo de negocio del e-commerce, no se había formalizado del todo hasta después de la presencia del COVID-19, dado que, existen componentes que han impedido que los de la región del Austro, realicen compras de forma online, por miedo a estafas, o al no contar con tarjetas de crédito y/o débito para realizar los pagos, usualmente la cultura de las personas radica en el hecho de comprar en forma presencial y no virtual, el desconocimiento en el proceso de compra en sitios web, es otro factor incidente.

La presente investigación, hace referencia al comercio electrónico en la Región 6 del Austro, que incluye las ciudades de Azogues, Cuenca y Macas, como dinámica de la productividad. Cabe destacar que el comercio online ha tomado un gran espacio en la economía a nivel local, regional, nacional y mundial en estos tiempos, una buena parte del comercio se ha realizado de forma electrónica ya que resulta más fácil adquirir los productos de esta manera, por la comodidad pues evita al consumidor salir a buscar en tiendas físicas y también es un ahorro de tiempo; entre los productos y servicios más requeridos son alimentos, supermercados, farmacias, licoreras, lavanderías, regalos, artículos y herramientas menores.

El comercio electrónico todavía es joven y se está formando, y el futuro se ve brillante para las empresas que se deciden a conducir sus negocios en línea, solo hay que mirar a las empresas como Amazon.com y eBay.com, como se ha posesionado en el mercado online y las utilidades y beneficios que estas han generado. 
Este trabajo es parte del proyecto de investigación denominado "La importancia de la información contable y financiera ante la incertidumbre del COVID-19 en las Mipymes en el entorno de los negocios en la región 6", el mismo que se justifica porque contribuye desde una perspectiva teórica académica a dar salida a la importancia de los modelos de negocios del e-commerce en las micro, pequeñas, y medianas empresas en tiempos de pandemia.

\section{Metodologia}

En este apartado de la investigación corresponde examinar algunos aportes teóricos sobre emprendimiento, se utilizó para llevar a cabo el estudio, indicando el paradigma de investigación positivista, tipo de investigación diseño de campo no experimental y transeccional o transversal con apoyo documental, Según, Tamayo (2003) establece que en la investigación de campo, los datos se recogen directamente de la realidad, razón por lo que se les denomina primarios, lo cual, según el precitado autor su valor radica en que permite cerciorarse de las verdaderas condiciones en que se han obtenido los datos, lo cual facilita su revisión o modificación en caso de surgir dudas (p.65).

El nivel de investigación fue la investigación descriptiva, según, Arias (2016), que: "La investigación descriptiva consiste en la caracterización de un hecho, fenómeno, individuo o grupo, con el fin de establecer su estructura o comportamiento" (p.24).

Se corresponde, por tanto, con el nivel descriptivo en función del objetivo general planteado, la población estuvo estructurada por tres sectores escogidos de microempresas, considerando la base del catastro del SRI del 2021, así Azuay con 45.814, Cañar 10.497 y Morona Santiago 11.300, total 67.611 microempresas de la Zona 6 del Austro, de las cuales son empresas registradas en la Superintendencia de Compañías por el año 2021 en Azuay 8.843, Cañar 494 y Morona Santiago 341, total 9.678, dando un gran total de 77.289, se determinó el tamaño de la muestra con un 4,50\% de error, determinándose por tanto la muestra $n=471$, la validez de contenido fue realizado mediante el juicio de tres expertos con experiencia en el área de financiera, contabilidad y metodología.

Por su parte, fue importante analizar en primer lugar, la pertinencia del coeficiente de consistencia interna de Cronbach, la misma trata sobre el grado en que los ítems miden la homogeneidad. Para determinar la confiabilidad del cuestionario elaborado, se procedió aplicar una prueba piloto a 30 empresas, que no forman parte de la muestra, todos ellos con características similares a los sujetos de este estudio, administrando una escala, de 7 ítems, a una muestra de $n=30$. De acuerdo con los resultados anteriores, se concluyó que la escala tiene una confiabilidad de consistencia interna muy alta, suficiente como para ser considerada fiable. En conclusión, la confiabilidad del instrumento fue de 0,9 muy alta, así mismo, fue sustancial la utilización de la herramienta estadística para el desarrollo de la investigación, recurriendo a la estadística descriptiva, lo que permitió la recolección, organización, análisis y presentación de datos con el apoyo de cuadros, tablas, figuras y los resultados obtenidos de la aplicación de los cuestionarios en relación con los objetivos planteados del presente estudio, mediante el software libre SPSS, versión 26. 
El análisis de los datos es una parte esencial de toda investigación, en tal sentido, Hernández et al. (2016), sostienen que "el procedimiento que se sigue para analizar los datos consiste en: Una vez que los datos se han codificado, transferido a una matriz, guardado en un archivo y "limpiado" los errores, el investigador procede a analizarlos utilizando un programa computacional" (p. 272). En base a lo cual se procedió a inspeccionar, limpiar y transformar datos con el objetivo de resaltar información útil, lo que sugiere conclusiones, y apoyo a la toma de decisiones.

Posterior a los procedimientos que condujeron a reunir datos con el propósito específico de estructurar un análisis de la normativa financiera, se procedió a revisar los datos o respuestas obtenidas mediante Google forms. Las respuestas a los cuestionarios se recopilan de forma automática y ordenada en formularios, con figuras y datos de las respuestas en tiempo real, que fueron procesados, analizados e interpretados, considerando el uso de la triangulación, validez, confiabilidad y contrastación de los instrumentos.

\section{Fundamentación Teórica}

El marco teórico referencial comprende aspectos teóricos, conceptuales, legales, situacionales de la realidad que forma parte de la presente investigación, garantizando de esta manera la integración e interrelación de la teoría con la metodología y objetivos de investigación.

Según, La Conferencia de las Naciones Unidas (2020), sobre comercio y desarrollo, la UNCTAD, que es un laboratorio de ideas que brinda apoyo a los países en desarrollo en materia de comercio, de inversiones y de financiación; el sector del comercio electrónico experimentó un gran crecimiento en las ventas al por menor, pasando del $16 \%$ al $19 \%$ en 2020. El aumento se vio impulsado por las restricciones a la circulación adoptadas por varios países para luchar contra la pandemia del COVID-19. En este orden de ideas señala que la mayor alza porcentual de ventas minoristas se produjo en la república de Corea del Sur con el país asiático creciendo de un 20,70\%, en el año 2019 a un 25,90\% el 2020. Así mismo, otras alzas destacadas durante el mismo ejercicio económico, se produjeron en el Reino Unido aumentando del 15,80\% al 23,30\%; igualmente en la China del 20,70\% al 24,90\%; Estados Unidos del 11\% al 14\%, Australia del 6,30\% al 9,40\% y Singapur del $5,90 \%$ al $11,70 \%$.

De igual manera, en la Conferencia de las Naciones Unidas- UNCTAD (2020), se sustenta que, en las últimas apreciaciones disponibles, las ventas del comercio electrónico a nivel global en el año 2019, incluyendo las ventas entre empresas y de empresa a consumidor, alcanzaron los 26,70 billones de dólares, un aumento del 4\% con respecto a 2018. La cifra equivale al 30\% del producto interior bruto mundial del año 2019. Por tales razones estas estadísticas evidencian la creciente importancia del comercio electrónico, por ello la necesidad de los países, especialmente los que están en vías de desarrollo, dispongan de esta información mientras reconstruyen o reactivan sus economías tras las secuelas que está dejando la pandemia del COVID-19. 
Según, La Comisión Económica para América Latina y el Caribe- CEPAL (2019), El conocimiento sobre cómo las empresas de América Latina y el Caribe usan Internet para involucrarse en el comercio, y en particular los desafíos que enfrentan para adoptar y usar el comercio electrónico para exportar bienes y servicios, es aún bastante incipiente, en consecuencia el propósito de este documento es analizar los desafíos que enfrentan las empresas de América Latina y el Caribe en su comercio electrónico, mediante la explotación de datos de encuestas que cubren a más de 1.430 empresas de la región, junto con datos económicos y de consumo, así como entrevistas con firmas digitales. También propone algunas recomendaciones de políticas sobre cómo las economías regionales pueden trabajar juntas para potenciar el comercio electrónico transfronterizo en la región.

La Comisión Económica para América Latina y el Caribe- CEPAL (2021), actualmente, el comercio electrónico es uno de los sectores de mayor actividad. Su auge a nivel global se debe principalmente a factores, como: avance de la tecnología, crecimiento de la masa de compradores, mayor alcance al acceso en las conexiones, uso de canales digitales de la banca, aumento de la oferta de productos en canales virtuales y nuevos hábitos de consumo por parte de las personas quienes prefieren comprar online por sus distintas ventajas; y es que con la presencia de la pandemia en el país, muchos se vieron forzadas a realizar sus compras habituales a través de transacciones electrónicas; para algunos esto significaba una nueva experiencia, mientras que para otros se tradujo como el incremento de una conducta previamente adquirida. El 2020 marcó un antes y un después en el comercio online. El contexto obligó a las marcas y a los profesionales del sector a realizar esfuerzos para adaptarse a toda velocidad a la nueva realidad y al nuevo consumo.

Posteriormente, El Banco Interamericano de Desarrollo- BID junto con la Comisión Económica para América Latina y Caribe- CEPAL y la Fundación Konrad Adenauer Programa Regional de Alianzas para la Democracia y el Desarrollo de América Latina ADELA (2021), dejan saber sobre la importancia de empoderar a América Latina y Caribe para un mejor aprovechamiento del comercio electrónico y digital frente a la pandemia de COVID-19. Durante el webinar se presentó el reporte de "Recuperación económica tras el coronavirus, para empoderar a América Latina y el Caribe para un mejor aprovechamiento del comercio electrónico y digital", elaborado conjuntamente por el BID, CEPAL y KAS, seguido de un panel de alto nivel de autoridades públicas y directivos del sector privado vinculados al comercio electrónico y digital, se deduce que este encuentro permitió conocer cómo la pandemia COVID-19 ha impactado en los flujos de comercio electrónico y digital en América Latina y Caribe y en otras regiones en desarrollo, además de conocer los desafíos y oportunidades del comercio electrónico y digital para apoyar la reactivación económica.

En el caso del Ecuador, según revista Ekos, La Cámara Ecuatoriana de Comercio Electrónico (2021), el comercio electrónico en Ecuador alcanzó un volumen de negocio de USD 2.3 mil millones, lo que supone un crecimiento de USD 700 millones (43,75\%) frente al 2019. Para el 2021 se estima un crecimiento no menor a un doble dígito. Igualmente sostiene que en el año 2020 marcó un antes y un después en el comercio online. El contexto obligó a las marcas y a los profesionales del sector a realizar esfuerzos 
para adaptarse a toda velocidad a la nueva realidad y al nuevo consumo, es así como uno de cada tres compradores eligió por primera vez el canal online para generar sus compras, además reportó un crecimiento del $800 \%$ en visitas a los sitios webs y un $44 \%$ en órdenes en comparación con 2019, según las últimas estadísticas de la Cámara Ecuatoriana de Comercio Electrónico (CECE).

En consecuencia, la definición de e-commerce se traduce a la "transacción de bienes y servicios que se realiza entre un comprador y un vendedor, mediante una plataforma electrónica o en internet. El comercio electrónico se puede desarrollar entre EmpresaConsumidor o Empresa-Empresa", (Price Waterhouse Coopers, 2020).

Así mismo, Cisneros (2016), sostiene que en la actualidad, basta con ingresar a google y digitar la palabra e-commerce para obtener un sin número de conceptos, quizás unos más complejos que otros; sin embargo, dado que el objetivo radica precisamente en hacer que lo complejo sea lo más sencillo posible, una definición más sintetizada de este fenómeno sería establecerlo como aquella actividad económica basada en el ofrecimiento de productos o servicios, ya sea para su compra o su venta, a través de medios digitales como internet, por tales razones, esta actividad, con todas sus prácticas específicas, implica una nueva forma de hacer negocios y representa el camino que actualmente muchas empresas están eligiendo recorrer para consolidarse o continuar expandiéndose.

En tal sentido, cuando un negocio entra en el ámbito de internet, Elsempeter (2013), manifiesta que se abre la operación en condiciones que nunca podría tener si se encuentra limitado a una tienda en una avenida. Los beneficios para la empresa son magníficos. Si se diseña y se realiza el comercio electrónico correctamente, se tendrán grandes ventajas en las finanzas de la empresa, así como mayor rapidez para hacer llegar los productos y servicios al mercado; también se alcanzarán nuevos clientes, incluso la empresa más diminuta parecerá una enorme rueda.

De igual forma, Hunt (2012), sostiene que la razón fundamental de ser de la mayoría de empresas de negocio es crear para los dueños unos valores máximos que puedan sostenerse. De allí que existe un motivo para estar en un negocio que busca rentabilidad, ganar dinero, ya sea un puesto de limonadas sobre la calle o una empresa multinacional con miles de empleados, el único motivo por el que desea que ingrese su organización en internet es ganar dinero, y mucho, si es posible ganar fortuna en internet. Tomamos como ejemplo a Jeff Bezos, el fundador de Amazon.com. Empezando con sólo tres estaciones de trabajo y un sueño, convirtió su cochera, en los suburbios de Seattle, en la historia de éxito más grande de Internet. Su éxito impulsó su fortuna personal a 10.5 miles de millones de dólares, e hizo que Amazon.com fuese un nombre conocido por todo el mundo.

Según, Becerra \& Calle (2021), sostienen que cuando se quería vender algo, había que rentar una tienda, contratar empleados, llenar los anaqueles, gastar algo de dinero en publicidad, tal vez enviar por correo algunos catálogos, y esperar a que los clientes llegaran o a que enviaran por correo sus pedidos. Todo esto se escucha muy bien; después de todo, es la manera en que se han efectuado convencionalmente los negocios, pero con 
el internet de su lado, el tiempo entre el desarrollo de su producto o servicio, y tenerlo listo para el cliente se ha estrechado considerablemente, de allí que una tienda virtual se puede organizar y actualizar en tiempo real, sumado a ello, permite prescindir del uso del papel y ahorrar costos por concepto de impresión, por consiguiente en el mundo del comercio electrónico es recomendable siempre pensar en los beneficios que prodiga tener una tienda virtual, porque, solo siendo conscientes de ello, sostienen que se podrá trabajar de manera organizada sacando lo mejor.

No obstante, Morán (2012), manifiesta que la informática, es una ciencia que estudia los procedimientos que tienden a reducir o suprimir la intervención humana de diferentes actividades de la información y métodos, realizadas de una manera sistematizada y veloz, a través de los computadores, es así que está ligado con las disciplinas y técnicas debido a que la tecnología es un componente importante del comercio electrónico, los cambios en el negocio son más difíciles de manejar por su magnitud total, debido a estos cambios, por ello que el valor de la compañía no se encuentra en los activos tangibles, como productos y materiales, en consecuencia el valor se encuentra en los intangibles tales como la marca, relaciones con los clientes e integración de proveedores.

En relación al precio, Elsempeter (2013), la mayoría de veces que una persona ingresa a la web para poder buscar un determinado producto o servicio, pese a que siempre está la opción de adquirir sin más el de mayor calidad, el cibernauta no dejará pasar la oportunidad de comparar los precios, toda vez que en el internet todo resulta más accesible; fácilmente podrá darse el lujo de comparar los precios yendo y viniendo de una web a otra en escasos minutos. Es por ello que las grandes empresas optan por tener una estrategia de precios más agresiva e incluso algunas se hacen con un software que les permita analizar los precios de la competencia y estar así siempre un paso adelante con respecto de la oferta, de esa manera, se puede ver, entonces, que el comercio trae consigo una nueva dinámica de precios al mercado.

Entre los tipos de precios usados en el comercio electrónico es posible encontrar al llamado precio máximo, el mismo que toma en cuenta factores como el inventario de la competencia o el hecho de si determinados productos se venden bastante en ciertas épocas como la navideña, el día de la madre, entre otras. Por otra parte, el segundo es el precio en función del tiempo, estará establecido según el mes del año o la hora del día en que la empresa decide lanzar su plataforma de productos, podría incluso hablarse de precios segmentados.

Es importante que todos aquellos ecuatorianos que estén relacionados con el uso del comercio electrónico, nos encontremos con total conocimiento sobre la Ley de Comercio Electrónico (2014), que sostiene la necesidad de impulsar el acceso de la población a los servicios electrónicos que se generan por y a través de diferentes medios electrónicos y que a través del servicio de redes electrónicas, incluida la internet, se establecen relaciones económicas y de comercio, y se realizan actos y contratos de carácter civil y mercantil. 
En tal sentido las ciudades del Austro de la región 6, se han sumado a este modelo de intercambio, los canales convencionales de compra, mediante las plataformas tecnológicas y las aplicaciones móviles Android y Apple (IOS), de allí que se puede notar la continua penetración del comercio electrónico, por medio de las compras por internet, esta realidad obliga a los negocios locales a desarrollar nuevos modelos de ventas, ya que la carrera tecnológica en esta materia seguirá creciendo y este apogeo tendrá un precio alto para los dueños de comercios que no apliquen herramientas tecnológicas, esto lo reconoce inclusive las cámaras de la producción de la ciudad de Cuenca.

\section{Resultados}

Para el procesamiento y análisis de la información proporcionada por las micro, pequeñas y medianas empresas, en el presente trabajo de investigación, fue necesario acudir a la técnica de la encuesta y el instrumento del cuestionario, en un total de 30 ítems, seleccionando únicamente cinco por ser los más notables.

\section{Figura 1}

Canales actuales de atención a clientes y usuarios

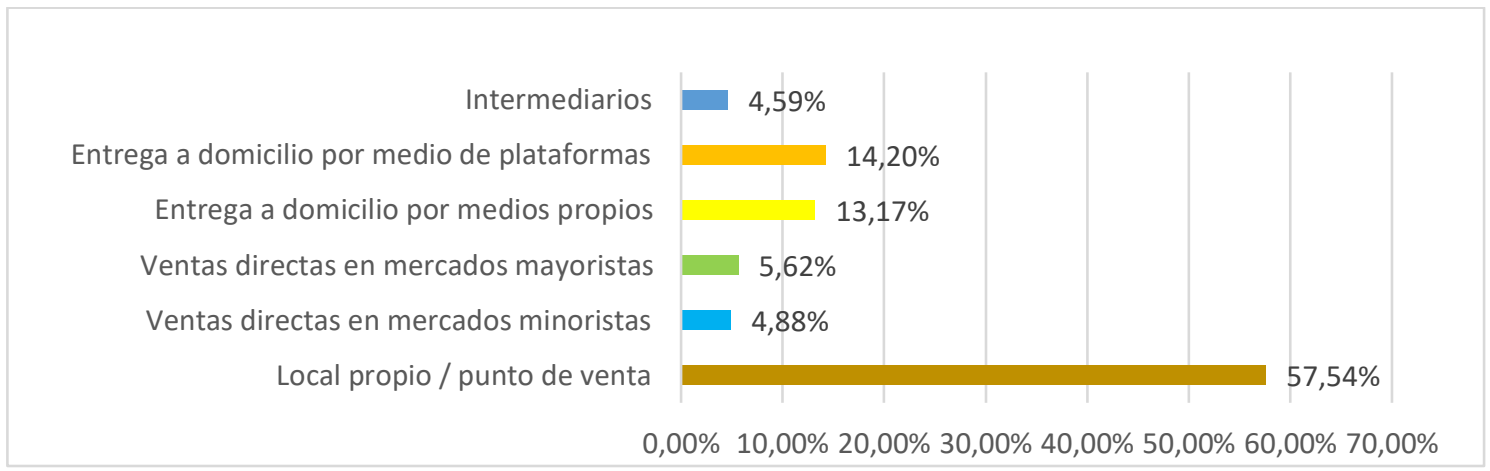

Fuente: Elaboración propia (2021). Tomado del proyecto de investigación la importancia de la información contable y financiera ante la incertidumbre del COVID-19 en las Mipymes en el entorno de los negocios en la región 6.

La información recogida permitió determinar que los actuales canales de distribución de los productos o servicios con un $57.54 \%$ se han mantenido a través de ventas en el local propio o el punto de venta, el 14,20\% de empresas realizan ventas a través de entregas a domicilio por medio de plataformas, un $13.7 \%$ han realizado sus ventas mediante entregas a domicilio por medios propios, el 5.62\% realizan ventas directas en mercados mayoristas, el $4.88 \%$ de encuestas hacen ventas directas en mercados minoristas y finalmente un $4.59 \%$ realizan ventas a través de intermediarios, de allí durante la pandemia, las restricciones limitaron considerablemente las ventas físicas pero, aun así, la venta promedio creció especialmente en los sectores de supermercados, comidas, farmacias, artículos e implementos deportivos, entre otros, de igual forma fue necesario realizar ventas a domicilio mediante plataformas tecnológicas y pedidos por llamadas telefónicas, desde que inició la pandemia claramente vimos una reducción de la movilidad, relacionada a las medidas restrictivas, sin embargo, un gran sector productivo no paró y mediante el servicio delivery, y la utilización de una "app" pudo vender sus 
productos, en medida de ello es necesario establecer estrategias que ayuden a un manejo eficaz, seguro y eficiente de sus ventas.

\section{Figura 1}

Costos adicionales, en los que ha incurrido la empresa

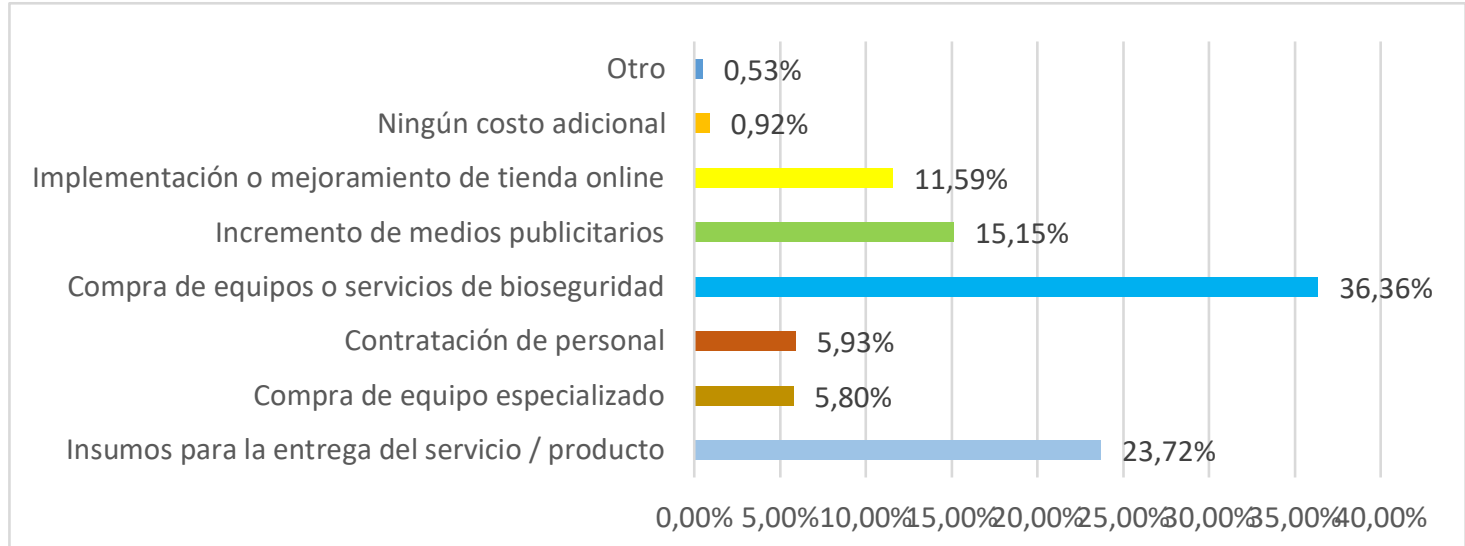

Fuente: Elaboración propia (2021). Tomado del proyecto de investigación la importancia de la información contable y financiera ante la incertidumbre del COVID-19 en las Mipymes en el entorno de los negocios en la región 6.

El análisis indico que el $36.36 \%$ de los ejecutivos empresariales encuestados afirmaron haber incurrido en gastos a través de la compra de equipos o servicios de bioseguridad, así también un $23,72 \%$ han destinado dinero a insumos para la entrega del servicio o producto, el $15.15 \%$ de las empresas ha visto necesario pagar para incrementar su publicidad, el $11.59 \%$ ha incurrido en gastos para la implementación o mejora de su tienda online, la contratación de personal ha sido otro de las gastos a los que el 5,93\% de las empresas han tenido que incurrir, el 5,80\% ha comprado equipo especializado, únicamente el $0,92 \%$ señala no haber incurrido en ningún tipo de gasto y finalmente el $0.53 \%$ asegura haber mantenido otro tipo de gastos. Esto crea diferentes escenarios para las empresas, ya que al tener que gastar en insumos para la distribución de sus productos o servicios, es decir, estos son costos adicionales por medio de las cuales diferentes empresas han tenido que afrontar la pandemia para poder sacar adelante sus negocios, las diferentes organizaciones se han adaptado de su habitual forma de comercio a la situación actual, por ello han tenido que adquirir como el caso de las casas de salud equipos y las empresas insumos de bioseguridad, consistentes en desinfectantes, detergente enzimático para lavado de instrumental, jabón líquido neutro y alcalino, gel antibacterial, o gelificador de líquidos biológicos y por otra parte algunas empresas se han visto en la necesidad de la implementación o mejoramiento de sus tiendas online, por ello que usar el comercio electrónico en los negocios resulta más económico que tener una tienda física y permite ofrecer más promociones a su clientes. 


\section{Figura 2}

Medidas que ha tomado su empresa tras la crisis por la pandemia del COVID 19

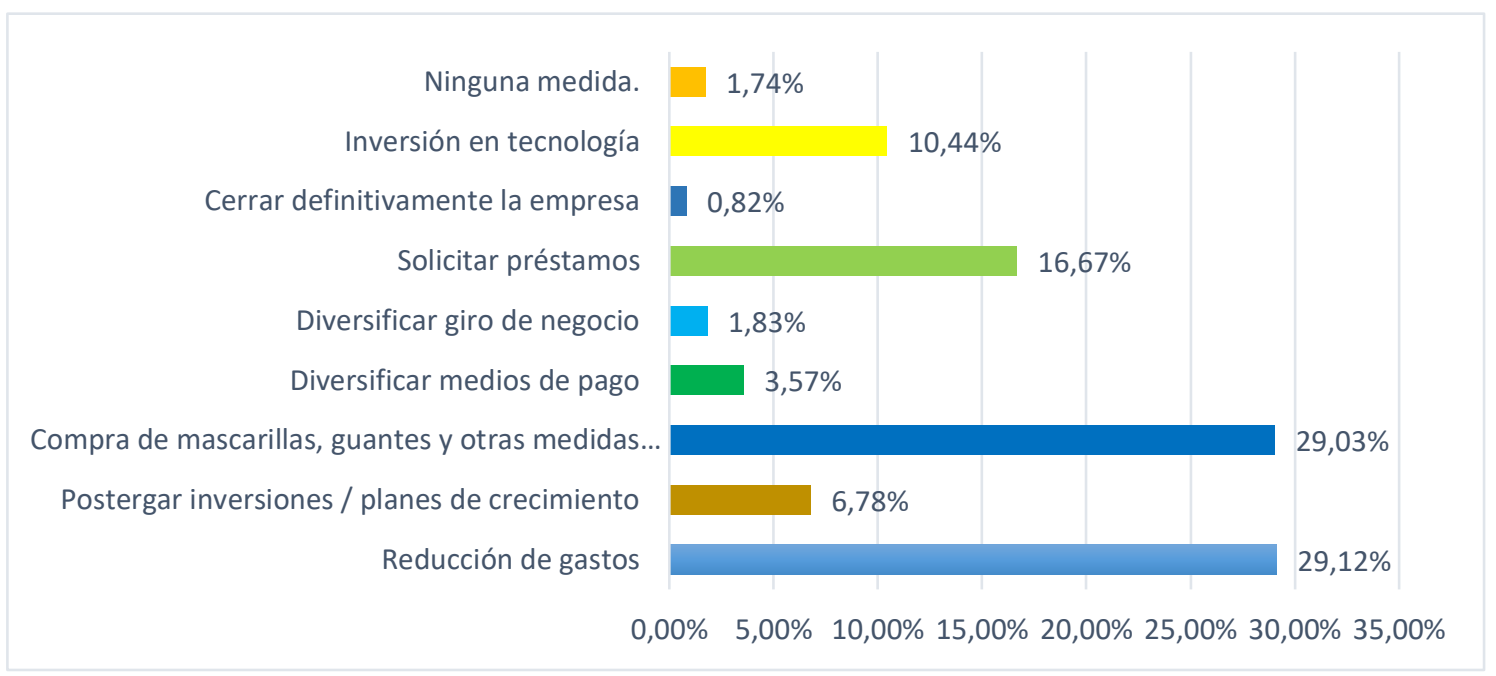

Fuente: Elaboración propia (2021). Tomado del proyecto de investigación la importancia de la información contable y financiera ante la incertidumbre del COVID-19 en las Mipymes en el entorno de los negocios en la región 6.

Según, el grafico $\mathrm{N}^{\circ} 3$, el $29,12 \%$ de los encuestados mencionan haber reducido sus gastos, esto en relación a las medidas tomadas tras la crisis por la pandemia, mientras que el $29.03 \%$ ha realizado la compra de mascarillas, guantes y otras medidas de limpieza, el $16.67 \%$ ha solicitado prestamos, el 10,44\% de las empresas encuestadas ha invertido en tecnología, mientras que el $6.78 \%$ ha postergado inversiones así como planes de crecimiento, el $3.57 \%$ ha diversificado medios de pago, el 1,74\% no ha aplicado ninguna medida, el $1,83 \%$ ha diversificado dándole un giro al negocio, $0,82 \%$ ha cerrado definitivamente la empresa. En medida de ello las diferentes estrategias asumidas para enfrentar el periodo de pandemia, y con ello poder sobrellevar la crisis existente, sin embargo, se ve un gran porcentaje que compromete la compra de insumos de bioseguridad lo cual, si bien aporta a la situación actual de salud, representa un gasto y por tanto esto incide en la liquidez de las empresas, por esa razón, es importante indicar que una buena parte de las empresas tuvo menos ingresos durante la pandemia, las formas de comercio redujeron o suspendieron turnos y redujo la jornada laboral, esto con el fin de reducir los gastos para hacerle frente a la crisis, otra variable a tener en cuenta fueron el tener que acudir a instituciones financieras, para solicitar préstamos a objeto de tener liquidez que necesitan para afrontar los gastos y obligaciones con proveedores, trabajadores, obligaciones tributarias y con la seguridad social, entre otros, fue necesario también invertir en tecnología. Invertir en esta área implica disponer recursos, económicos, técnicos y humanos, tanto en la concepción del uso de la tecnología, de igual forma en cómo se utilizará la misma de manera segura y eficaz, además de la sistematización de procesos, e implementación y mejora del comercio electrónico. 


\section{Figura 3}

Opciones para la reactivar económicamente las empresas

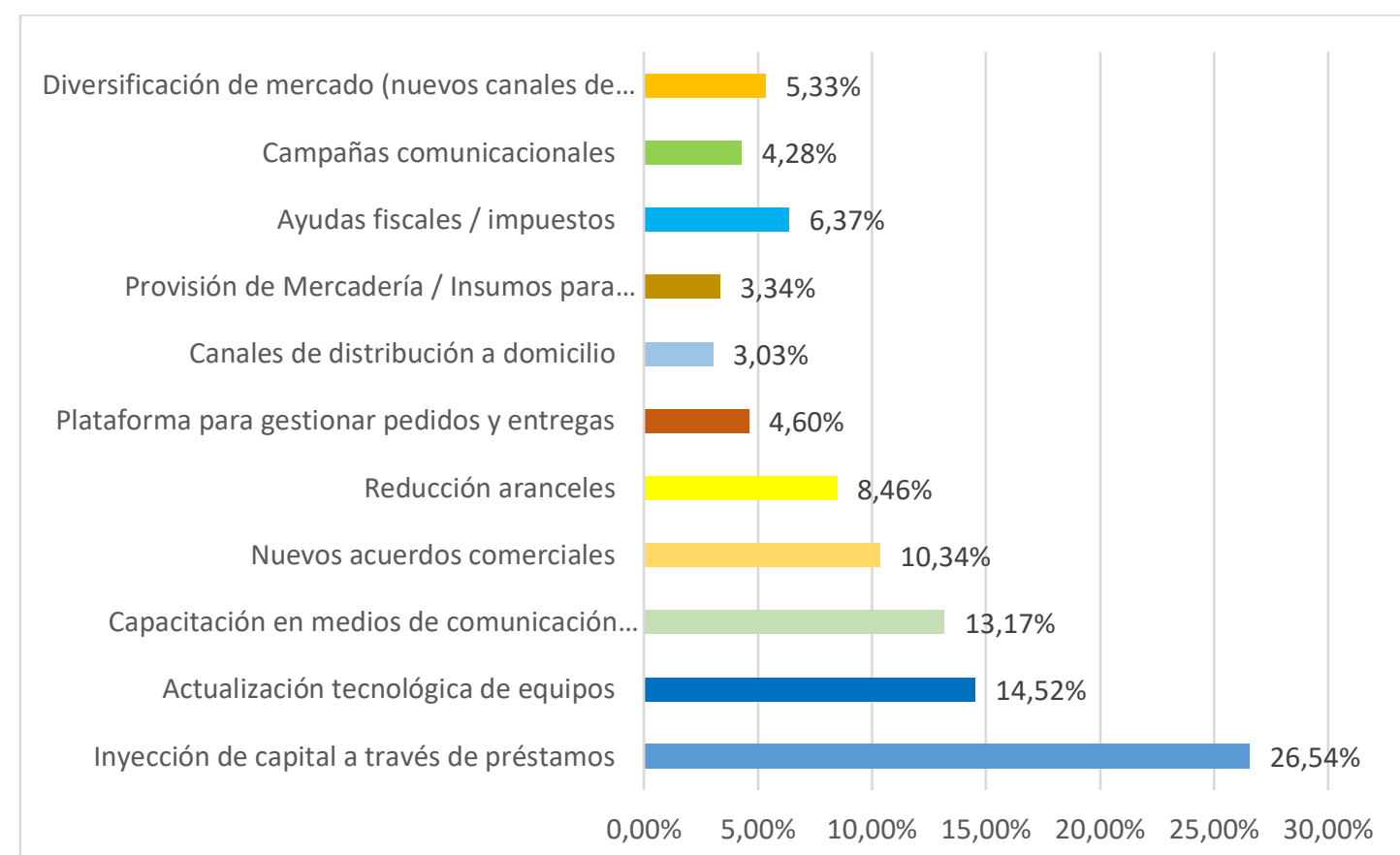

Fuente: Elaboración propia (2021). Tomado del proyecto de investigación la importancia de la información contable y financiera ante la incertidumbre del COVID-19 en las Mipymes en el entorno de los negocios en la región 6.

Las actividades que se considerarían para reactivar económicamente a la empresa corresponde en un $26,54 \%$ inyección de capital a través de préstamos, seguido de un $14,52 \%$ que prefieren realizar una actualización tecnológica de los equipos, el $13.17 \%$ piensa que realizar capacitaciones en medios de comunicación digitales sería de gran ayuda, así mismo el $10.34 \%$ pretende establecer acuerdo comerciales, el $8.46 \%$ cree necesario la reducción de aranceles, el $6.37 \%$ pretende ayudas fiscales e impuestos, el $4.60 \%$ desea crear una plataforma para gestión de pedido y entregas, el $4.28 \%$ campañas comunicacionales, el $3.34 \%$ provisión de mercadería e insumos para producción, $3.03 \%$ de canales de distribución a domicilio. Cada una de las alternativas son bastante valederas a la hora de gestionar de una mejor manera las empresas, de entre las variables más relevantes esta la inyección de capital por parte de los socios y accionistas, y del préstamo que ofrecen las entidades bancarias, que permitan una planificación financiera en tiempos de pandemia que le permita a las empresas tener liquidez para atender sus obligaciones más apremiantes y continuar con su productividad y generación del comercio, así mismo sumado las tendencias de plataformas para gestionar pedidos y canales de distribución a domicilio, se ve un alto interés en participar dentro de las estrategias del e-comerce, lo cual son acciones que en el país y la región, es algo bastante nuevo, pero que a razón de la situación se ha tenido que implementar, lo que ha creado alternativas de comercio mucho más efectivas y cómodas. 


\section{Figura 4}

Servicios requeridos mediante el comercio electrónico.

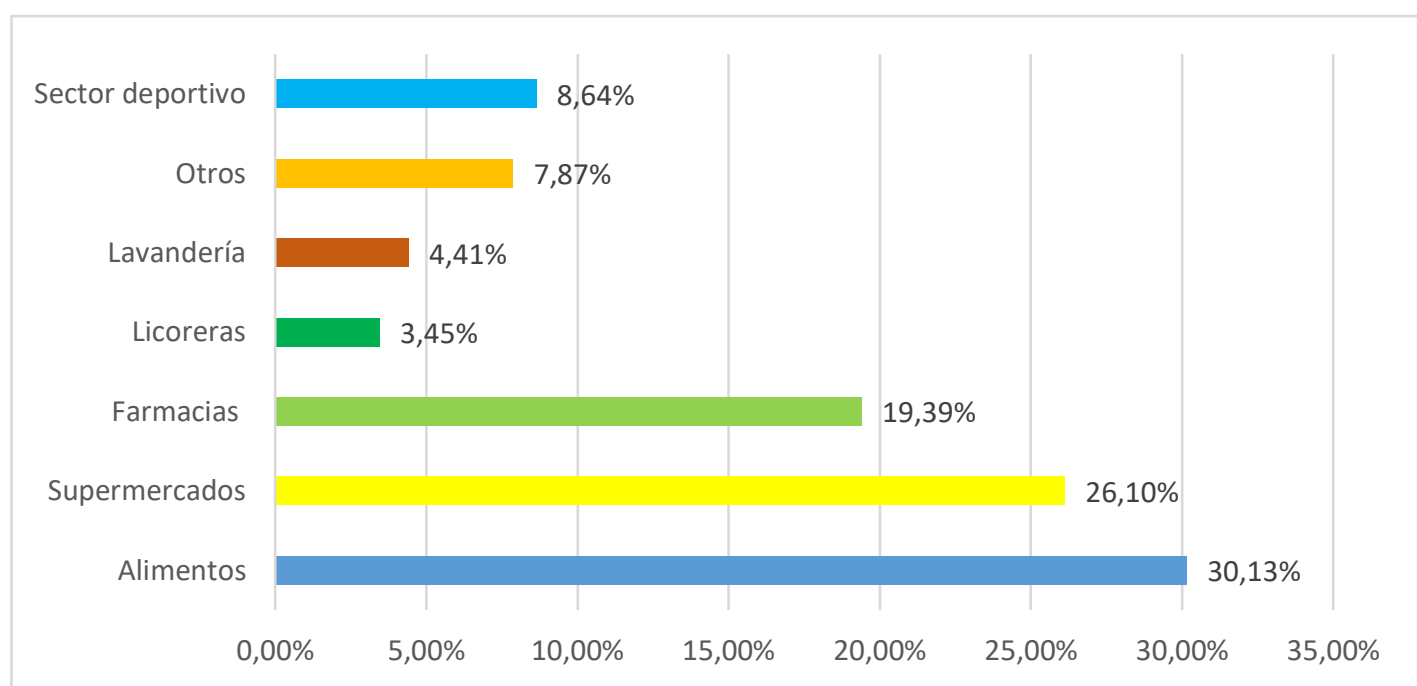

Fuente: Elaboración propia (2021). Tomado del proyecto de investigación la importancia de la información contable y financiera ante la incertidumbre del COVID-19 en las Mipymes en el entorno de los negocios en la región 6.

Como resultado de la gráfica $\mathrm{N}^{\circ} 5$, las actividades los servicios requeridos mediante comercio electrónico anta la presencia del COVID-19, fueron alimentos con el 30,13\%, supermercados con el 26,10\%, farmacias con el 19,39\%, sector deportivo el 8,64\%, que incluye equipos como caminadoras electrónicas, bicicletas, indumentaria, bicicletas, zapatos, etc., otros el 7,87\%, que incluye contenido audiovisuales, computadoras, celulares, artículos y otras herramientas, lavandería con el 4,41\% y licoreras con el 3,45\%, en definitiva el cambio más claro es el que más personas han tomado la decisión de optar por las compras online para evitar salir a la calle y exponerse al coronavirus, de allí que a nivel de la región 6 del Austro, los ingresos del e-commerce han crecido, no obstante, también destaca que la disposición de los consumidores en la región para recurrir a las compras online; estas han experimentado un crecimiento exponencial durante el año 2020, actualmente, es posible encontrar prácticamente todo tipo de productos en Internet o plataformas online, procedentes de no solo la región 6, y el país, sino de cualquier rincón del planeta.

\section{Discusión}

La presencia del coronavirus en Ecuador no sólo está afectando la salud de sus habitantes, sino en varios contornos de la humanidad como son la educación, salud, transporte público, seguridad, trabajo, el comercio, posiblemente nadie contaba con que llegaría un virus que forzaría a millones de personas a recluirse en sus hogares y cambiar considerablemente sus hábitos de consumo y la forma en que realizan sus compras, beneficiando en cierta forma con ello a los distintos negocios que presentan la opción de compras en línea y dando un empujón general a todo el concepto del comercio electrónico. 
Según, Becerra y Calle (2020), la información recogida, da cuenta que el comercio electrónico elimina la necesidad de una tienda física, por tanto, la empresa puede ahorrar dinero en arrendamiento, mantenimiento, servicios públicos y contratación de personal. Además, dado que no hay límite para la cantidad de artículos que se pueden vender en línea, las existencias de una tienda virtual pueden expandirse de manera exponencial en un modelo de comercio electrónico, y puede permanecer abierta las 24 horas para que los consumidores puedan comprar sus productos a la hora que deseen; respecto al tema de los hábitos, el cambio más claro es que han aumentado individuos que han tomado la decisión de preferir las compras online de productos o servicios vía comercio electrónico, para evitar salir a la calle y exponerse a la pandemia,

Así mismo, Velte (2016), afirma que no es ningún secreto que el comercio electrónico es la última y la mayor ola en el comercio, el negocio no había sufrido un cambio tan fantástico, tanto para el vendedor como para el comprador. Se trata de la convergencia entre la profesión más vieja del mundo, es decir vender cosas, con la tecnología de este milenio, que implican las computadoras. El crecimiento del comercio electrónico ha sido exponencial, y las historias de éxito son ya legendarias debido al incremento de usuarios durante los años 2020 y 2021.

Del mismo modo, Elsempeter (2013), manifiesta que, para tener éxito en el comercio electrónico, ya no es posible pensar en términos de la operación con paredes y cemento, los gerentes, los directores ejecutivos y los presidentes deben sencillamente también pensar en una estrategia de un plan de negocios en línea y conducirlo como siempre. Toda vez que el comercio electrónico es un matrimonio entre los negocios y la tecnología, resulta indispensable comprender el lado tecnológico de esta unión, así como la forma en que la tecnología y el negocio que ya existe y la práctica de integrar tecnología a su negocio.

Velascos et al. (2021), sostienen que el modelo de negocio del e-commerce en Ecuador es algo que ha venido de forma paulatina. La cultura ecuatoriana está acostumbrada a realizar compras de forma presencial, ya que se percibe un ambiente de seguridad en el proceso de compra-venta; sin embargo, la pandemia del COVID-19, hizo que las personas realicen sus compras de forma online, y de cierto modo, romper esas barreras de miedo que no permitían al cliente comprar en internet.

Por su parte, Cisneros (2016), manifiesta que cada vez que el cibernauta ingresa a una sección de la tienda virtual, esta debe señalar en qué parte del conjunto del sitio se encuentra el visitante, así mismo debe mantener el orden de los productos siempre es una muy buena idea, esto permitirá tener presente el precio, según cuál es el más barato o el más caro, o de acuerdo a cuál es el más nuevo, innovado o el más antiguo, además es necesario exponer los productos con fotos y descripción a fin de que los potenciales clientes se entusiasmen con lo que ofrecen las micro, pequeñas y medianas empresas, por tanto un escenario así representa una buena oportunidad para los negocios que ya tienen presencia online y para los que están considerando hacerlo y capitalizar la oportunidad acelerando el lanzamiento de su portal para el comercio electrónico. 
Es conveniente señalar que todos aquellos ecuatorianos que estén relacionados con el uso del comercio electrónico, nos encontremos con total conocimiento sobre La Cámara Ecuatoriana de Comercio Electrónico- CECE. (2014), que sostiene la necesidad de impulsar el acceso de la población a los servicios electrónicos que se generan por y a través de diferentes medios electrónicos y que, a través del servicio de redes electrónicas, incluida la internet, se establecen relaciones económicas y de comercio, y se realizan actos y contratos de carácter civil y mercantil.

La Cámara Ecuatoriana de Comercio Electrónico- CECE. (2021), sostiene que es conveniente destacar la educación a la oferta, que implica profesionalizar la misma que existe en comercios en línea, sean productos y servicios, o por cualquier canal no presencial; otorgar conocimientos específicos para brindar una mejor experiencia, igualmente es necesario entender la demanda, ya que las empresas deben identificar y diferenciar los productos que los usuarios prefieren comprar vía online y cuáles prefiere comprar de manera presencial; esto permitirá tener un panorama más claro, difundir los beneficios de comprar online y realizar los ajustes necesarios para brindar una mejor experiencia e interacción online, en torno a fortalecer la relación público-privada, es necesario estrechar alianzas entre la empresa privada con el Gobierno para efectuar una mejor toma de decisiones y al diseño de estrategias que sean beneficiosas para ambas partes y para el país a nivel de tributos y en condiciones de mercado. Trabajar de manera mancomunada para difundir las ventajas y mejoras en temas como: logística y medios de pago, en cuanto a mejorar el alcance de la bancarización, resultará importante otorgar facilidades para que las personas se encuentren bancarizadas, esto permitirá generar un ecosistema de formalidad en el sector, aumentando la confianza de los consumidores para realizar transacción y compra electrónica, en torno a mejorar el alcance de digitalización de diversos sectores facilitando el acceso a dispositivos, como en el ancho de banda de Internet; esto no solo como vía para dinamizar la economía a través del comercio electrónico, sino para facilitar el teletrabajo y teleeducación.

Así mismo, Becerra et al. (2021), es importante señalar que, a través del portal web de la Cámara Ecuatoriana de Comercio Electrónico, se coloca a disposición de sus usuarios productos de primera necesidad, comida, bebidas; además su contenido es gratuito para acceder a webinars (clases en línea), sumado a una mínima parte de artículos electrónicos, entre otros, generando un atractivo que permite ingresar a las arcas fiscales algo de impuestos por la facturación del sitio.

Según, Becerra et al. (2021), en su artículo medidas financieras en el entorno de los negocios, para minimizar los efectos de la pandemia COVID-19, nutren sobre la importancia a la implementación o mejoramiento de las tiendas online, es decir tiendas virtuales o tiendas electrónicas, un tipo de comercio que usa las bondades de la tecnología y el comercio electrónico como herramientas esenciales para realizar sus transacciones a través de un sitio web o una aplicación conectada a Internet.

De igual forma, Becerra et al. (2021), en el artículo la importancia de la información contable ante la incertidumbre del Covid-19, en las Mipymes en el entorno de los 
negocios en la región 6, en su análisis de los ingresos por actividades ordinarias, de las empresa, mencionan que se incorporó el comercio electrónico, es decir decidieron tratar de acoplarse a la nueva forma de ventas a causa del COVID 19, de allí que los negocios han sido afectadas debido a la situación actual de pandemia mundial y han realizado ventas a través de internet lo cual ha hecho que se avance en materia de comercio en línea.

Como es lógico, el comercio electrónico está teniendo un momento importante con todo y que también puede presentar retos para las marcas y consumidores, en estos meses y para los que vienen, el tráfico a los distintos sitios sigue aumentando, a raíz que la calamidad pública producida por la detección de casos de COVID-19 variantes Alfa, Beta, Delta y Gamma del Covid-19 son mutaciones del SARS-COV-2 persiste, ahora nos preguntamos, ¿Será este un evento que dejará huella en el e-commerce cuando todo el problema quede atrás, se mantendrá las ventas online?. No obstante, se estima que el coronavirus tendrá un impacto a largo plazo dentro de los hábitos de compra de los consumidores. Usar el comercio electrónico en los negocios resulta más económico que tener una tienda física y permite ofrecer más promociones, al tiempo que es un canal para conocer más al cliente.

\section{Conclusiones}

A continuación, se exponen las principales conclusiones, integrando los resultados de los cuestionarios, y la técnica de la observación:

- La información recogida en los gráficos $\mathrm{N}^{\circ} 1$, sostiene que en los meses más fuertes de la llegada de la pandemia existieron locales como los comisariatos, locales de comida, farmacias entre otros atendieron en un 57,54\% desde sus locales propios y puntos de venta, sin descuidar el servicio delivery, para ello fue necesario la compra de insumos de bioseguridad en un 36,36\%, conforme la gráfica $\mathrm{N}^{\circ} 2$, y el $23,72 \%$, para la venta de los productos y servicios, con el fin de preservar la salud del personal de directivos y trabajadores, además de los clientes y usuarios, que se articula a su vez con el grafico $\mathrm{N}^{\circ} 3$, en el $29,12 \%$, toda vez se tuvo que reducir costos y gastos por la disminución de horas de trabajo, suspensión total o parcial del empleo, por la escasez o falta de recursos para el desarrollo de la actividad empresarial como consecuencia de la pandemia, fue necesario también en el 29,03\% la compra de mascarillas, guantes, alcohol, gel antiséptico y otras medidas de bioseguridad, de allí que el comercio electrónico, fue una opción para acceder los productos o servicios, y en consecuencia, fue la estrategia de algunos negocios para generar algunos ingresos, mediante sus ventas.

- El análisis de los gráficos $\mathrm{N}^{\circ} 4$ con respecto a la inyección de capital los resultados determinaron que el 26,54\%, ya sea mediante aportes de los dueños de los negocios o de las reservas o aportes de socios y accionistas, o por ultimo mediante diferimiento de pagos y solicitud de préstamos para atender las más acuciantes obligaciones con proveedores y trabajadores, fue necesario también actualización 
tecnológica de equipos, nuevos acuerdos con clientes y proveedores, actualización tecnológica, plataformas para gestionar pedidos y despachos, canales de distribución a domicilio, diversificación de nuevos productos, esto se articula con la gráfica $\mathrm{N}^{\circ} 5$ con respecto a los servicios requeridos, y una de las estrategias para generar algo de ingresos fue el comercio electrónico, que entre los servicios más demandados fueron alimentos con el 30,15\%, supermercados con el 26,10\%, farmacias el 19,39\% y demás servicios como sector deportivo, computadoras, celulares, y demás accesorios y herramientas menores, además de los servicios de licoreras y lavandería, mediante plataformas, telefonía celular y el servicio delivery, la información proporcionada permitió determinar que abrir una tienda virtual resulta más económico que una tienda física, de allí que tener un canal online aumenta la ventaja competitiva de la empresa porque ante el público se mostrará como una empresa que está al día con las nuevas tecnologías e innovación y creatividad para sus clientes.

- En la actualidad, el e-commerce se ha fortalecido en tres pilares fundamentales: la logística que está relacionada con el proceso de entrega del producto, el marketing digital la cual se enfoca en la publicidad y promoción de la marca; y, por último, la administración financiera enfocada al buen uso del dinero. Estos pilares han hecho que este modelo de negocio vaya en incremento, ofreciendo productos y/o servicios que transcienden las fronteras locales y/o nacionales, de forma segura, rápida, cómoda y sobre todo a costos bajos.

- Es conveniente destacar, que habitamos en un mundo globalizado, en donde la era de la información o informática digital lo es todo hoy en día; y, por tanto, la humanidad que va de la mano con los cambios tecnológicos, podrá mejorar elocuentemente su estilo de vida y por ende contribuir para el cumplimiento de los objetivos de desarrollo y reactivación económica de las Mipymes.

- Concluyentemente el comercio digital va creciendo en los hogares de la región del Austro, porque la presión del ingreso obliga a los consumidores a reconformar su gasto y sus compras, lo que también es necesario que las compañías modifiquen sus estrategias, así como percibimos que los consumidores con alto poder adquisitivo aumentarán el comercio online, considerando ciertos factores de la comodidad o necesidad de comprar por urgencia o conveniencia.

- El análisis indicó, que nuevas pautas de consumo y fortalecimiento de la cadena de valor de las ventas online, constituyen algunos de los saldos que ha arrojado la pandemia del COVID-19, si bien ha afectado la salud y diversas actividades económicas, trae consigo el generar ideas que pertenecen al ámbito de la creatividad e invención, al paso que la innovación es utilizar ideas para obtener recursos, además de transformar dichas ideas en dinero, y así contribuir al desarrollo de soluciones de negocios que ayudarán al crecimiento del eCommerce a corto plazo.

- Es importante señalar, que el comercio electrónico brinda a los clientes y usuarios la oportunidad de buscar productos más económicos y de calidad, por consiguiente, los consumidores pueden investigar fácilmente un producto 
específico y, a veces incluso encontrar el fabricante original para comprar un producto a un precio mucho más barato que el que ofrece un distribuidor.

- En el e-commerce, las empresas tendrán un repunte a los niveles que ya tiene o incluso más elevados una vez que acabe la pandemia, lo que es un hecho, es que todo este escenario ha logrado destacar la importancia que tiene el apartado digital de los negocios, sin duda, más de una empresa ha podido comprobar que tener una tienda en línea puede llegar a ser crucial en tiempos extraordinarios como estos, pero también puede ser un buen recurso en un contexto normal dentro de la actividad comercial empresarial.

\section{Referencias bibliográficas}

Arias, F. (2016). El Proyecto de Investigación: Introducción a la metodología científica. ( $7^{\text {a }}$ Edición), Caracas - Venezuela. Editorial El pasillo, C.A.

Becerra, E. \& Calle, O. (2020). El comercio electrónico en la región del Austro, como dinámica de la productividad. Conciencia Digital, 3(4), 6-25.

Becerra, E., Cuadrado, G. \& Flores, M. (2021). Medidas financieras en el entorno de los negocios, para minimizar los efectos de la pandemia COVID-19. Conciencia Digital, 4(3), 211-231.

Becerra, E., Jaramillo, Y., \& Astudillo, P. (2021). La importancia de la información contable ante la incertidumbre del Covid-19, en las Mipymes en el entorno de los negocios en la región 6. Visionario Digital, 5(3), 111-132.

Becerra, E., Flores, M., \& Cuadrado, G. (2021). La fiscalidad en las Mipymes de la región del Austro, en el contexto de la pandemia del COVID-19. Alpha publicaciones, 3(3), 98-119.

Cisneros, E. (2016). Comercio electrónico. Primera edición, Lima- Perú. Editorial Macro EIRL.

Conferencia de las Naciones Unidas -UNCTAD (2020), El comercio electrónico mundial crece hasta los 26,7 billones de dólares, impulsado por la COVID-19, recuperado de: https://news.un.org/es/story/2021/05/1491592

Elsempeter, R. (2013). Fundamentos del Comercio Electrónico, McGraw-Hill interamericana, México, D.F. Editores, S.A: de C.V.

Hernández, S., Fernández, C., \& Baptista, L. (2016). Metodología de la Investigación. México: Mc Graw Hill Educación, 6ta. Edición.

Hunt, D. (2012). Financiación Básica de los negocios, Pearson Hunt, DCS. México, D.F. Editores, Hispano Americana.

La Cámara Ecuatoriana de Comercio Electrónico- CECE. (2014). El comercio electrónico mantendrá un crecimiento sostenido en Ecuador, recuperado de: 
https://www.ekosnegocios.com/articulo/en-2021-el-comercio-electronicomantendra-un-crecimiento-sostenido-en-ecuador

La Cámara Ecuatoriana de Comercio Electrónico- CECE. (2021). En el 2021, el comercio electrónico mantendrá un crecimiento sostenido en el país, recuperado de: https://revistagestion.ec/empresas/en-el-2021-el-comercio-electronicomantendra-un-crecimiento-sostenido-en-el-pais

La Comisión Económica para América Latina y el Caribe- CEPAL (2019). El comercio digital en América Latina ¿Qué desafíos enfrentan las empresas y cómo superarlos, recuperado de: https://www.cepal.org/es/publicaciones/44976comercio-digital-america-latina-que-desafios-enfrentan-empresas-comosuperarlos

La Comisión Económica para América Latina y el Caribe- CEPAL (2021). El rol del comercio electrónico y digital en la reactivación económica en América Latina y el Caribe, recuperado de: https://events.iadb.org/calendar/event/24329?lang=es

Ley de Comercio electrónico, Firmas y mensajes de datos, (2014), Esta Ley fue publicada en el Suplemento del Registro Oficial N ${ }^{\circ}$ 557, del 10 de febrero del 2014.

Morán, F. (2012). Computación Educativa, Primera edición, Guayaquil- Ecuador. Editorial departamento de educación a distancia de la Universidad de Guayaquil.

Price, Waterhouse, C. (2020). E-Commerce en Ecuador. Obtenido de https://www.pwc.ec/es/publicaciones/assets/e-commerce-ecuador.pd

Tamayo, M. (2003). El Proceso de Investigación Científica (4a edición). México. Editorial Limusa.

Velascos, B., Castellanos, E., \& Miranda, M. (2021). El e-commerce en las empresas ecuatorianas. un análisis de los informes de la cámara ecuatoriana de comercio electrónico (CECE) en el marco de la pandemia COVID-19. Revista Publicando, $8(29), 13-20$.

Velte (2016), Desarrollo de estrategias para atraer clientes, generar ventas y manejar su negocio por internet con eficacia, McGraw-Hill interamericana, México, D.F. Editores, S.A: de C.V.

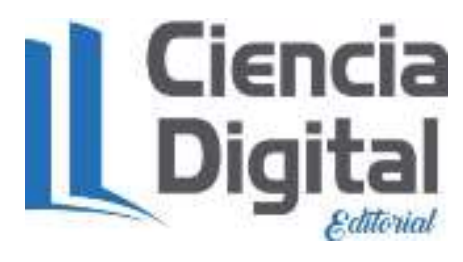




\section{PARA CITAR EL ARTÍCULO INDEXADO.}

Becerra Molina , E., Jaramillo Calle , Y., \& Eliza Flores, M. (2021). El comercio electrónico en tiempos de COVID-19, en el entorno de los negocios de la región 6 . Ciencia Digital, 5(4), 94-113. https://doi.org/10.33262/cienciadigital.v5i4.1872

\section{Ciencia \\ Ligital}

El artículo que se publica es de exclusiva responsabilidad de los autores y no necesariamente reflejan el pensamiento de la Revista Ciencia Digital.

El artículo queda en propiedad de la revista y, por tanto, su publicación parcial y/o total en otro medio tiene que ser autorizado por el director de la Revista Ciencia Digital.
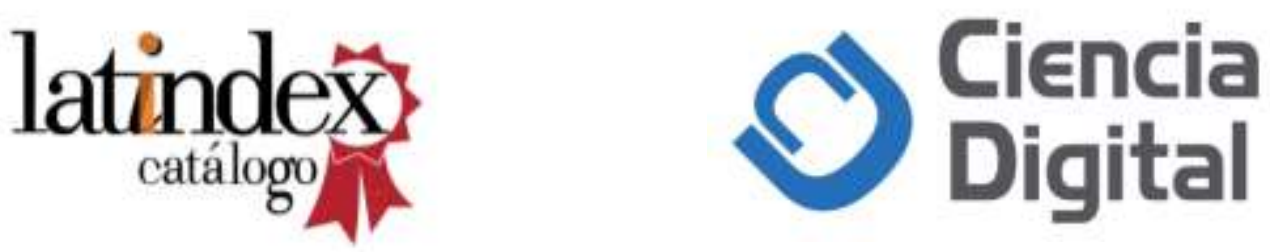